\title{
Molecular Differentiation of Fusarium solani f. sp. glycines from Other F. solani Based on Mitochondrial Small Subunit rDNA Sequences
}

\author{
Shuxian Li, Yan Kit Tam, and Glen L. Hartman
}

First and third authors: Department of Crop Sciences, National Soybean Research Center, University of Illinois, Urbana 61801; second author: Department of Microbiology and Immunology, Albert Einstein College of Medicine, Bronx, NY 10461; third author: United States Department of Agriculture-Agriculture Research Service, 1101 W. Peabody, Urbana, IL 61801-4723.

Accepted for publication 25 January 2000.

\begin{abstract}
Li, S., Tam, Y.-K., and Hartman, G. L. 2000. Molecular differentiation of Fusarium solani f. sp. glycines from other $F$. solani based on mitochondrial small subunit rDNA sequences. Phytopathology 90:491-497.

Fusarium solani is a soilborne plant pathogen that infects many different hosts. Within the species, there is some specialization, and a number of forma specialis have been described based on host affiliation. One of these, $F$. solani $\mathrm{f}$. sp. glycines, infects soybean and causes sudden death syndrome. To differentiate between $F$. solani f. sp. glycines and other $F$. solani isolates, a partial sequence of the mitochondrial small subunit (mtSSU) rRNA gene was amplified by polymerase chain reaction and sequenced from $14 F$. solani f. sp. glycines and $24 F$. solani isolates from various plant hosts. All $F$. solani f. sp. glycines isolates had identical sequences. A single, unique insertion of cytosine occurred in all $F$. solani isolates but not in any of the $F$. solani $\mathrm{f}$. sp. glycines isolates. Two major

lineages, distinguished by sequence divergence and the presence or absence of multiple insertions, occurred in $F$. solani isolates. Cladistic analysis produced a single most-parsimonious tree with three major clades. The first clade contained all $F$. solani f. sp. glycines isolates. A second clade grouped together all of the $F$. solani isolates that had only a single nucleotide insertion difference from the first clade. Genetic distance between these two clades was 0.016 . A third clade was formed by five $F$. solani isolates that had multiple insertions. Isolates in the third clade had a genetic distance of 0.040 from the first and second clades. Based on the sequence data, it is likely that $F$. solani f. sp. glycines has a shorter evolutionary history than other $F$. solani isolates that have either single or multiple nucleotide insertions. The differences in nucleotide insertions in part of the mtSSU rRNA gene between $F$. solani $\mathrm{f}$. sp. glycines and other $F$. solani isolates provide a direct and reliable way to distinguish isolates of $F$. solani.
\end{abstract}

Sudden death syndrome (SDS) is an economically important soybean disease $(11,38)$. The symptoms of SDS include root rot and vascular discoloration of roots and stems. The most conspicuous symptoms of SDS occur on leaves, beginning with chlorotic mottling and proceeding to interveinal chlorosis, necrosis, and defoliation. The causal organism, Fusarium solani (Mart.) Sacc. f. sp. glycines (30), is a soilborne fungus first identified in 1989 (31,32). Previously, nomenclature designated $F$. solani form A for SDScausing $F$. solani and form B for the $F$. solani seedling and root rot pathogen that did not cause SDS (30). In addition, $F$. solani $\mathrm{f}$. sp. glycines SDS-causing isolates were reported to form chlamydospores (21) similar to some other F. solani isolates (6) and were reported to produce mostly macroconidia rather than microconidia $(30,31)$.

In the past, identification of $F$. solani $\mathrm{f}$. sp. glycines has relied on morphological and cultural characteristics. However, in culture, isolates often differ in phenotypic traits, such as colony morphology, pigment production, and sporulation. For example, blue pigmentation in cultures of some $F$. solani $\mathrm{f}$. sp. glycines isolates varied from light to dark, and some of the isolates did not produce

Corresponding author: G. L. Hartman; E-mail address: ghartman@uiuc.edu

Names are necessary to report factually on available data; however, the United States Department of Agriculture (USDA) neither guarantees nor warrants the standard of the product, and the use of the name by USDA implies no approval of the product to the exclusion of others that may also be suitable.

Publication no. P-2000-0321-01R

This article is in the public domain and not copyrightable. It may be freely reprinted with customary crediting of the source. The American Phytopathological Society, 2000. the blue pigment $(30,33)$. However, some of the $F$. solani nonSDS-causing isolates appeared blue (25). The morphologically based classification system has not provided an accurate tool for the identification of $F$. solani $\mathrm{f}$. sp. glycines and has not resolved the relationship of isolates within the $F$. solani complex.

A molecular approach based on discrete DNA sequence data offers considerable promise in the establishment of an objective, phylogenetically based system for the classification of Fusarium species $(4,9,26)$. O'Donnell and Gray (27) analyzed the phylogenetic relationship of several species within the $F$. solani complex based on nuclear ribosomal DNA sequences. In their study, SDS-causing isolates were grouped with $F$. solani f. sp. phaseoli. Results from random amplified polymorphic DNA (RAPD) analysis (1) showed that $F$. solani SDS-causing isolates formed a cluster that represented a biological meaningful subgroup within $F$. solani f. sp. phaseoli, and it was suggested that the subgroup represents a separate form species. Understanding the molecular relationship between $F$. solani f. sp. glycines that causes SDS and other $F$. solani will provide insight in the specific identification and detection of $F$. solani f. sp. glycines.

In many organisms, mitochondrial DNA has a higher rate of evolution than nuclear DNA (2). It has been reported that the base substitutions per nucleotide are roughly 16-fold greater in the mitochondrial small subunit (mtSSU) rRNA gene than in the nuclear small subunit rRNA gene in 10 members of mushrooms in the order Boletales (3). Mitochondrial DNA may serve as a useful alternative to differentiate closely related species for phylogenetic analysis of fungi other than nuclear genes (3).

Restriction enzyme fragment length polymorphisms (RFLPs) of mitochondrial DNA have been used for biological variation studies in Aspergillus spp. (17), Cochliobolus heterostrophus (8), strains 
of Neurospora spp. (5), F. oxysporum $(13,14,16)$, and Glomerella (Colletotrichum) spp. (37). Sequence analysis of the mtSSU rDNA has been used in fungal identification, specific primer development, and phylogenetic studies $(19,28)$. However, extensive studies in the mtSSU rDNA of $F$. solani $\mathrm{f}$. sp. glycines have not been reported. The objectives of our study were to (i) analyze the molecular differences and relatedness between $F$. solani f. sp. glycines and other $F$. solani isolates based on mtSSU rDNA sequences and (ii) evaluate the potential use of the mtSSU rDNA region for differentiation of $F$. solani f. sp. glycines from other $F$. solani isolates. Preliminary results were recently reported (22).

\section{MATERIALS AND METHODS}

Fungal isolates and culture morphology. The host affiliation, geographic origins, and sources of the fungal isolates used for polymerase chain reaction (PCR) amplification and sequencing of the partial mtSSU rDNA in this study are listed in Table 1. In addition to $14 \mathrm{~F}$. solani $\mathrm{f}$. sp. glycines isolates, $24 \mathrm{~F}$. solani non-SDScausing isolates from 9 hosts were used. All isolates were maintained either on $2 \%$ water agar or potato dextrose agar (PDA) at $4{ }^{\circ} \mathrm{C}$ or air-dried and kept at room temperature.

For cultural and morphological studies, isolates were grown on PDA plates, sealed with Parafilm, incubated at 23 to $25^{\circ} \mathrm{C}$ in the dark, and examined after 5 to 20 days. After inoculation, colony color was determined based on a mycological color chart (29). Growth rates were determined by measuring the colony diameter after inoculation in triplicate PDA plates at 5 days. To examine the conidial types of the isolates, 2- to 3-week-old cultures were either directly examined with an Olympus BX60 microscope (Leco Co, Chicago) at 400,600 , or $1,000 \times$, or stained with $0.15 \mu \mathrm{g} / \mathrm{ml}$ of 4'-6-diamidino-2-phenylindole (Sigma-Aldrich Chemical Co., St. Louis) as described previously (21).

Pathogenicity tests and cultural filtrate toxicity assay. Soybean seeds of susceptible cv. Great Lakes 3202 were sown in Ray Leach Cone-Tainers (Stuewe \& Sons, Inc., Corvallis, OR) and inoculated with fungus-infested sorghum grains. Infested sorghum grain $\left(3 \mathrm{~cm}^{3}\right)$ was placed 2 to $3 \mathrm{~cm}$ below a soybean seed in each ConeTainer. Noninfested sorghum grain was used as a control. ConeTainers were placed in a growth chamber for a 12-h photoperiod with a light intensity of $300 \mu \mathrm{m}^{-2} \mathrm{~s}^{-1}$ at day and night temperatures of 28 and $22^{\circ} \mathrm{C}$, respectively. Seven plants were inoculated with each fungal isolate. Treatments (isolates) were arranged in a randomized complete block design with two replications. Foliar symptoms were recorded 28 days after planting with a 1 to 5 disease severity scale (10).

Cell-free culture filtrates were prepared from $F$. solani f. sp. glycines and other $F$. solani non-SDS-causing isolates. A total of 10 plugs ( $4 \mathrm{~mm}$ in diameter) from colony margins on $2 \%$ water agar plates were placed into $100 \mathrm{ml}$ of modified Septoria medium (34) and incubated at $25^{\circ} \mathrm{C}$ for 12 days. Cultures were filtered through Whatman No. 1 filter paper (Whatman Inc., Clifton, NJ) and sterile 0.22- $\mu \mathrm{m}$ membranes (Millipore Corp., Bedford, MA). Seedlings ( 3 weeks old) of cv. Great Lakes 3202 were cut and placed in test

TABLE 1. Fungal isolates used for polymerase chain reaction-amplification and sequencing of the partial mitochondrial small subunit ribosomal DNA in this study

\begin{tabular}{|c|c|c|c|c|}
\hline Isolate & Host/substrate & Geographic origin & Source or contributor & GenBank Accession no. \\
\hline \multicolumn{5}{|c|}{ Fusarium solani f. sp. glycines } \\
\hline Mont-1 & Glycines $\max$ & Illinois & P. Stevens & AF124995 \\
\hline $98-7$ & G. $\max$ & Illinois & S. Li & AF124996 \\
\hline B6-8v & G. $\max$ & Illinois & L. Gray & AF124997 \\
\hline VR309-1 & G. $\max$ & Illinois & L. Gray & AF124998 \\
\hline St 1-1 & G. $\max$ & Illinois & L. Gray & AF124999 \\
\hline AR269 & G. $\max$ & Arkansas & J. Rupe & AF125000 \\
\hline $17-1$ & G. $\max$ & Arkansas & J. Rupe & AF125001 \\
\hline Pcmo1 & G. $\max$ & Arkansas & J. Rupe & AF125002 \\
\hline NRRL $^{a} 22823$ & G. $\max$ & Indiana & L. Gray & AF125003 \\
\hline W1 & G. $\max$ & Wisconsin & L. Achenbach & AF125004 \\
\hline W4 & G. $\max$ & Wisconsin & L. Achenbach & AF125005 \\
\hline FSA-1 & G. $\max$ & Mississippi & C. Nickell & AF125006 \\
\hline $\mathrm{K}-1$ & G. $\max$ & Kansas & L. Gray & AF125007 \\
\hline BH-F2-13 & G. $\max$ & Iowa & X. Yang & AF125008 \\
\hline \multicolumn{5}{|l|}{ F. solani } \\
\hline 91-10-1-G & G. $\max$ & North Dakota & B. Nelson & AF125009 \\
\hline $95-115-3-\mathrm{A}$ & G. $\max$ & North Dakota & B. Nelson & AF125010 \\
\hline $95-32-1$ & G. $\max$ & North Dakota & B. Nelson & AF125011 \\
\hline $95-133-1$ & G. $\max$ & North Dakota & B. Nelson & AF125012 \\
\hline $95-41-1$ & G. $\max$ & North Dakota & B. Nelson & AF125013 \\
\hline $95-51-1$ & G. $\max$ & North Dakota & B. Nelson & AF125014 \\
\hline $95-109-1$ & G. $\max$ & North Dakota & B. Nelson & AF125015 \\
\hline NRRL $22820^{\mathrm{b}}$ & G. $\max$ & Indiana & T. Abney & AF125016 \\
\hline $\mathrm{T} 8$ & Pisum sativum & New York & H. Van Etten & AF125017 \\
\hline $6-36$ & $P$. sativum & New York & H. Van Etten & AF125030 \\
\hline 966 & P. sativum & Washington & P. Nelson & AF125018 \\
\hline 937 & P. sativum & Washington & P. Nelson & AF125019 \\
\hline F46 & $P$. sativum & Washington & J. Kraft & AF125020 \\
\hline D5 & Medicago sativum & Wisconsin & C. Grau & AF125021 \\
\hline 16-alfalfa & M. sativum & New York & P. Nelson & AF125022 \\
\hline NRRL 22382 & Phaseolus vulgaris & Germany & H. Nirenberg & AF125023 \\
\hline W-8-1-3R-I & P. vulgaris & Washington & J. Kraft & AF125028 \\
\hline Fsph- $2^{\mathrm{a}}$ & P. vulgaris & Washington & J. Kraft & AF125029 \\
\hline 3-bean & P. vulgaris & Idaho & C. Strausbaugh & AF125024 \\
\hline 71-tomato & Lycopersicum esculentum & California & A. Thornton & AF125025 \\
\hline 72-Pumpkin & Cucurbita pepo & California & A. Thornton & AF125027 \\
\hline 46-cucurbit & Cucurbita $\mathrm{sp}$. & California & A. Thornton & AF125031 \\
\hline 1-potato & Solanum tuberosum & Idaho & C. Strausbaugh & AF125026 \\
\hline 5-lupine & Lupinus spp. & Australia & E. Dann & AF125032 \\
\hline
\end{tabular}

a Northern Regional Research Lab, Peoria, Illinois.

b Nectria haematococca MPVI. 
tubes containing $25 \mathrm{ml}$ of fungal culture filtrates at 1:50 dilution ( $\mathrm{vol} / \mathrm{vol})$ with sterile distilled water. Disease severity of foliar symptoms was recorded daily from 3 to 10 days after stem immersion to examine whether any of culture filtrates caused soybean SDS-like foliar symptoms (23). The experiment was repeated at least once.

DNA extraction and PCR amplification. Fungal isolates were grown on PDA at 23 to $25^{\circ} \mathrm{C}$ for 10 to 15 days. Total genomic DNA was extracted from cultures on agar plates (20,35). PCR amplification of the mtSSU rDNA region was performed using the NMS1 and NMS2 primers, which were designed to amplify a portion of the mtSSU rRNA gene in ascomycetes (19). PCR was performed in a 50- $\mu$ l mixture that contained $0.2 \mathrm{mM}$ each of dATP, dCTP, dGTP, and dTTP; $50 \mathrm{mM} \mathrm{KCl} ; 10 \mathrm{mM}$ Tris-HCL at $\mathrm{pH} 8.3 ; 2.0 \mathrm{mM} \mathrm{MgCl} 2 ; 50$ pmol of primers; $50 \mathrm{ng}$ of genomic DNA, and $1 \mathrm{U}$ of Taq DNA polymerase (Perkin-Elmer Corp. Norwalk, CT). A negative control that excluded the DNA template was included in every experiment to test for reagent contamination. Amplification was performed with a GeneAmp PCR System 2400 DNA thermal cycler (Perkin-Elmer Cetus, Emeryville, CA) programmed as follows: 1 cycle at $94^{\circ} \mathrm{C}$ for $5 \mathrm{~min}$, followed by 30 cycles at $94^{\circ} \mathrm{C}$ for $30 \mathrm{~s}, 50^{\circ} \mathrm{C}$ for $60 \mathrm{~s}$, and $72^{\circ} \mathrm{C}$ for $90 \mathrm{~s}$. A 10 -min extension at $72^{\circ} \mathrm{C}$ was conducted after 30 cycles. PCR products were examined by electrophoresis of 5 - $\mu$ l aliquots on a 1.5 or $2 \%$ agarose gel, stained with ethidium bromide, and visualized with a UV transilluminator (Fotodyne Inc., Hartland, WI).

DNA sequencing. In all, 38 isolates, including $14 F$. solani f. sp. glycines and 24 other $F$. solani isolates, were sequenced for the NMS1- and NMS2-amplified mtSSU rDNA region. Prior to sequencing, PCR products were purified by filtration though Ultrafree-MC low-protein binding regenerated cellulose membrane filter units (NMWL) (Millipore) according to the manufacture's instructions.

Approximately 30 to $50 \mathrm{ng}$ of the purified PCR products was subjected to sequencing using the Dye Terminator Cycle Sequencing kit with an Applied Biosystem 373A sequencer (Perkin-Elmer Corp.). The conditions for the cycle-sequencing reactions were as follows: $1 \mathrm{~min}$ at $95^{\circ} \mathrm{C}$ for initial denaturation, followed by 25 cycles of $15 \mathrm{~s}$ at $95^{\circ} \mathrm{C}, 5 \mathrm{~s}$ at $45^{\circ} \mathrm{C}$, and $4 \mathrm{~min}$ at $60^{\circ} \mathrm{C}$. Primers NMS1 and NMS2 were used as sequencing primers for the first and second strand, respectively.

Sequence data analyses. DNA sequences were edited using Sequencher (Gene Codes Corp., Ann Arbor, MI) and aligned using the multiple sequences alignment program CLUSTAL W (36). All sequence data analyses were performed by the program PAUP*4.0b1 (Sinauer Associates Inc., Sunderland, MA). A matrix of genetic distances was generated using Kimura's two-parameter model (15). The mtSSU rDNA sequence of Nectria cinnabarina (provided by K. O'Donnell) was used as an outgroup in the data analysis. For neighbor-joining, the unweighted pair group method with arithmetic averages (UPGMA) and maximum likelihood analyses tree searches were done using all available characters, and gaps were either treated as missing data (748 characters for analysis) or excluded (617 characters for analysis). In all of the trees, the transition/ transversion ratio was equal to 2 . To assess the confidence level of each internal tree branch, 1,000 bootstrap replicates (7) were performed in the neighbor-joining and UPGMA analyses. To execute an exhaustive search for the best tree using maximum likelihood criterion, all $14 \mathrm{~F}$. solani f. sp. glycines isolates with identical sequences were represented by a single taxon, and one sequence was used to represent all identical $18 \mathrm{~F}$. solani non-SDS-causing isolates with a single nucleotide insertion in the analysis. The total number of taxa for the exhaustive search under this combination was nine.

Maximum parsimony analysis was conducted first by the exhaustive search option after combining isolates with identical sequences, followed by the heuristic search option for individual isolate sequences. Alignment gaps were treated in two ways, either as a fifth character state or as missing data. Uninformative characters (12) were excluded from the analysis; all characters were unordered and unweighted. The heuristic search option was performed using the tree bisection-reconnection branch swapping algorithm with 1,000 random addition sequences. Confidence levels of internal branches were assessed by 1,000 bootstrap replications.

\section{RESULTS}

Cultural and morphological characteristics. F. solani f. sp. glycines isolates grew slowly on PDA and generally formed appressed or semiappressed colonies that appeared reddish light to dark blue. Repeated subculturing or prolonged storage of cultures on PDA resulted in reduced sporulation and an increase in aerial mycelium. The coloration of individual $F$. solani non-SDS-causing isolates ranged from white to gray, yellow, pink-orange, blue, or purple. Most of the isolates produced aerial mycelium.

$F$. solani $\mathrm{f}$. sp. glycines isolates produced macroconidia that were mostly sickle shaped with four cells, but three-, five-, and six-celled macroconidia were occasionally found. In contrast, $F$. solani nonSDS-causing isolates predominately produced microconidia. However, there were some exceptions. For example, $F$. solani f. sp. phaseoli isolate NRRL 22382 and a soybean non-SDS-causing isolate, 95-133-1, produced both micro- and macroconidia.

Pathogenicity and toxicity. All $F$. solani $\mathrm{f}$. sp. glycines isolates caused SDS foliar symptoms beginning 10 to 12 days after inoculation. Disease severity on foliage ranged from 65 to $90 \%$ of the leaf area affected (Table 2). Other $F$. solani isolates tested did not cause SDS-like foliar symptoms, although some caused root rot or atypical foliar symptoms, such as yellow spots or chlorosis of leaf margins. F. solani f. sp. glycines isolates caused significantly $(P<0.01)$ higher disease severity on foliage, greater root lesion length, and a higher percentage of root lesions than other $F$. solani isolates.

Cuttings of soybean seedlings with their stems immersed in culture filtrates prepared from $F$. solani $\mathrm{f}$. sp. glycines isolates developed SDS-like foliar symptoms but not when immersed in filtrates of other $F$. solani isolates. Disease severity on foliage ranged from 55 to $86 \%$ of the leaf area affected when using filtrate from $F$. solani f. sp. glycines compared with 0 to $8 \%$ for filtrate from $F$. solani (Table 2).

Genetic divergence and phylogenetic analyses. All isolates studied gave strong amplification of a single PCR product in the mtSSU rDNA region using primers NMS1 and NMS2. Variations in the length of the amplified DNA fragment among isolates were observed through both agarose gel electrophoresis and DNA sequencing of the PCR products. All 14 isolates of $F$. solani $\mathrm{f}$. sp. glycines had identical length (626 bp) of the amplified fragment. All $F$. solani non-SDS-causing isolates had a longer amplified product than $F$. solani $\mathrm{f}$. sp. glycines isolates: 19 were $627 \mathrm{bp}$, with a single insertion of cytosine between the nucleotide positions 90 and 91 of the F. solani f. sp. glycines sequence. This single nucleotide insertion was present in all studied non-SDS-causing isolates but absent in the SDS-causing isolates. Five $F$. solani nonSDS-causing isolates had multiple insertions in two regions of the

TABLE 2. Range of foliar disease severity of soybean plants root-inoculated with Fusarium solani f. sp. glycine or F. solani and stems of cut soybean seedlings immersed in cell-free culture filtrates of $F$. solani f. sp. glycine or $F$. solani

\begin{tabular}{lccc}
\hline & & \multicolumn{2}{c}{ Foliar disease severity (\%) } \\
\cline { 4 - 4 } Fusarium sp. & No. tested & Root-inoculated $^{\mathrm{b}}$ & Stem cutting $^{\mathrm{c}}$ \\
\hline F. solani f. sp. glycine & 45 & $65-90$ & $55-86$ \\
F. solani & 50 & $0-10$ & $0-8$ \\
\hline
\end{tabular}

a The $F$. solani f. sp. glycine isolates caused soybean sudden death syndrome (SDS); the F. solani isolates did not cause SDS.

b Inoculated with infested sorghum grain (10).

c Li et al. (23). 
amplified fragment: between nucleotide positions 77 and 100 and between nucleotide positions 474 and 502 of the $F$. solani f. sp. glycines sequences (Fig. 1). The amplified fragment length of these five non-SDS-causing isolates ranged from 719 to $744 \mathrm{bp}$.

Pairwise genetic distances among all studied isolates based on the Kimura's two-parameter model are presented in Table 3. All $14 F$. solani $\mathrm{f}$. sp. glycines isolates had identical DNA sequences in the amplified mtSSU region. All $F$. solani non-SDS-causing isolates with a single insertion, except an isolate from pumpkin (72-pumpkin), also shared an identical DNA sequence of the amplified region among themselves and had a genetic distance of 0.016 from the sequence of $F$. solani f. sp. glycines. In contrast, the average genetic distance between $F$. solani non-SDS-causing isolates with a single insertion and those with multiple insertions was 0.040 , which is the same as the average genetic distance value $(0.040)$ between $F$. solani f. sp. glycines and $F$. solani isolates with multiple insertions.

When gaps were treated as a fifth character state, there was a total of 748 nucleotide characters; 133 were parsimony-informative and used in the maximum parsimony analysis. The most par- simonious tree resulted from the heuristic search with 1,000 random addition sequences, and the tree bisection-reconnection branch-swapping algorithm had a tree length of 214 and a consistency index of 0.8832 (Fig. 2). The same most parsimonious tree was the result of an exhaustive search after combining all isolates with identical sequences (data not shown). The next shortest tree had 215 steps, a length shared by two trees that had a consistency index of 0.8791 . Three trees had a tree length of 216 and a consistency index of 0.8750. All five of these trees clearly demonstrated the three major clades. The first clade was composed of all $F$. solani f. sp. glycines isolates. The second clade contained all $F$. solani non-SDScausing isolates possessing only a single extra nucleotide when compared with all $F$. solani f. sp. glycines. These two groups formed sister clades to each other. The third clade was formed by the five F. solani non-SDS-causing isolates with multiple insertions. The differences among the five shortest trees were on the arrangement of the isolates in the third clade, which had weak bootstrap values among branches within the clade (Fig. 2). There was no significant difference in tree topology when gaps were treated as missing data (tree not shown). However, bootstrap analysis indicated that

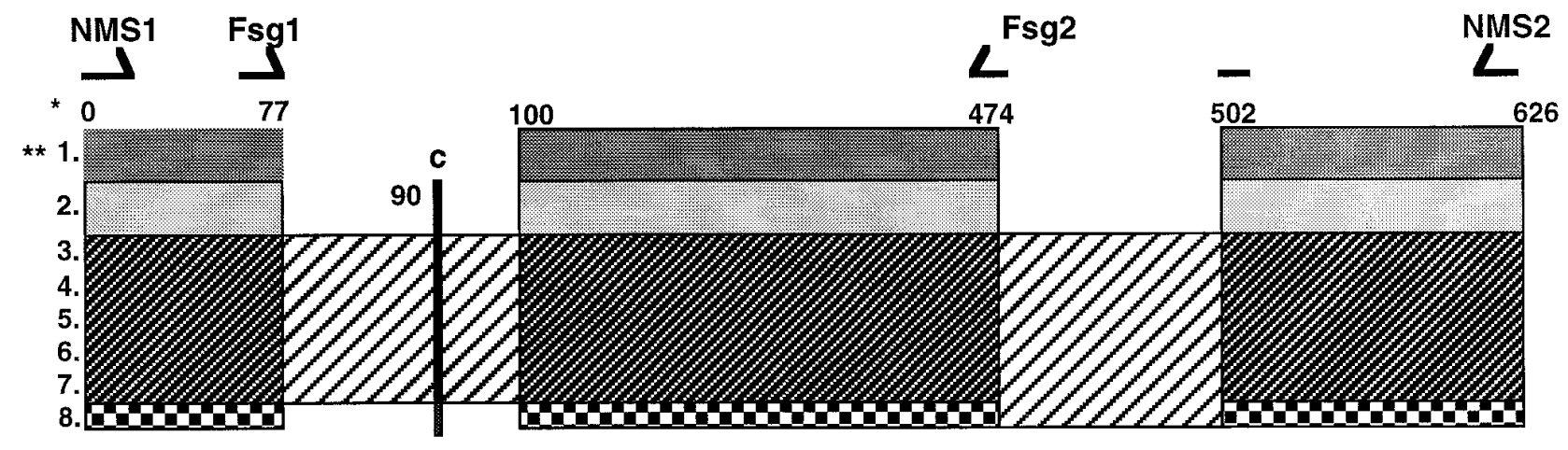

Highly variable regions with insertions for some FS non-SDS isolates.

Numbers indicate the positions according to FSG sequence.

\begin{tabular}{|c|c|c|c|c|}
\hline$\star \star$ & $\begin{array}{l}1 . \\
2 . \\
3 . \\
4 .\end{array}$ & $\begin{array}{l}\text { FSG (14 isolates) } \\
\text { FS (19 isolates) } \\
\text { FS, Fsph-2 (Bean) } \\
\text { FS, W8-1-3RI (Bean) }\end{array}$ & $\begin{array}{l}5 . \\
6 . \\
7 . \\
8 .\end{array}$ & $\begin{array}{l}\text { FS, 6-36 (Pea) } \\
\text { FS, 46-cucurbit (Cucurbit) } \\
\text { FS, 5-lupine (Lupine) } \\
\text { Nectria cinnabarina }\end{array}$ \\
\hline
\end{tabular}

Fig. 1. Schematic representation of the NMS1/NMS2 polymerase chain reaction-amplified DNA fragment. All Fusarium solani f. sp. glycines (FSG) isolates had identical sequences in this region. A single insertion of cytosine was present in all $F$. solani (FS) non-sudden death syndrome (SDS)-causing isolates sequenced but absent in all FSG isolates. Two highly variable regions with multiple insertions were shown in some FS non-SDS-causing isolates.

TABLE 3. Genetic distances between Fusarium solani f. sp. glycines (FSG) and other F. solani (FS) isolates, estimated using Kimura's two-parameter model

\begin{tabular}{|c|c|c|c|c|c|c|c|c|c|c|c|c|c|c|}
\hline Isolate/host & 1 & 2 & 3 & 4 & 5 & 6 & 7 & 8 & 9 & 10 & 11 & 12 & 13 & 14 \\
\hline 1. FSG (14 isolates)/soybean & $\ldots$ & 0.016 & 0.016 & 0.016 & 0.016 & 0.016 & 0.016 & 0.015 & 0.029 & 0.045 & 0.048 & 0.043 & 0.036 & 0.048 \\
\hline 2. FS (8 isolates)/soybean & $\ldots$ & $\ldots$ & 0.000 & 0.000 & 0.000 & 0.000 & 0.000 & 0.005 & 0.031 & 0.050 & 0.051 & 0.045 & 0.038 & 0.050 \\
\hline 3. FS (4 isolates)/pea & $\ldots$ & $\ldots$ & $\ldots$ & 0.000 & 0.000 & 0.000 & 0.000 & 0.005 & 0.031 & 0.050 & 0.051 & 0.045 & 0.038 & 0.050 \\
\hline 5. FS (2 isolates)/bean & $\ldots$ & $\ldots$ & $\ldots$ & $\ldots$ & $\ldots$ & 0.000 & 0.000 & 0.005 & 0.031 & 0.050 & 0.051 & 0.045 & 0.038 & 0.050 \\
\hline 6. FS (1-potato)/potato & $\ldots$ & $\ldots$ & $\ldots$ & $\ldots$ & $\ldots$ & $\ldots$ & 0.000 & 0.005 & 0.031 & 0.050 & 0.051 & 0.045 & 0.038 & 0.050 \\
\hline 7. FS 71-tomato/tomato & $\ldots$ & $\ldots$ & $\ldots$ & $\ldots$ & $\ldots$ & $\ldots$ & $\ldots$ & 0.005 & 0.031 & 0.050 & 0.051 & 0.045 & 0.038 & 0.050 \\
\hline 8. FS 72-pumpkin/pumpkin & $\ldots$ & $\ldots$ & $\ldots$ & $\ldots$ & $\ldots$ & $\ldots$ & $\ldots$ & $\ldots$ & 0.026 & 0.045 & 0.046 & 0.039 & 0.033 & 0.045 \\
\hline 11. FS 6-36/pea & $\cdots$ & $\ldots$ & $\ldots$ & $\ldots$ & $\ldots$ & $\ldots$ & $\ldots$ & $\ldots$ & $\ldots$ & $\ldots$ & $\ldots$ & 0.049 & 0.039 & 0.096 \\
\hline 12. FS 46-cucurbit/cucurbit & $\ldots$ & $\ldots$ & $\ldots$ & $\ldots$ & $\ldots$ & $\ldots$ & $\ldots$ & $\ldots$ & $\ldots$ & $\ldots$ & $\ldots$ & $\ldots$ & 0.014 & 0.085 \\
\hline 13. FS 5-lupine/lupine & $\ldots$ & $\ldots$ & $\ldots$ & $\ldots$ & $\ldots$ & $\ldots$ & $\ldots$ & $\ldots$ & $\ldots$ & $\ldots$ & $\ldots$ & $\ldots$ & $\ldots$ & 0.075 \\
\hline 14. Nectria cinnabarina & $\ldots$ & $\ldots$ & $\ldots$ & $\ldots$ & $\ldots$ & $\ldots$ & $\ldots$ & $\ldots$ & $\ldots$ & $\ldots$ & $\ldots$ & $\ldots$ & $\ldots$ & $\ldots$ \\
\hline
\end{tabular}


the branches were weaker in statistical support in this latter tree than in the one that resulted from treating gaps as the fifth character state.

Gaps were either treated as missing data or excluded from the analysis when the sequences were subjected to neighbor-joining, UPGMA and maximum-likelihood analyses. All these methods produced trees that shared topology similar to the maximum parsimonious tree in having the same three distinct clades and an identical arrangement of a clade containing all $F$. solani f. sp. glycines and its sister clade containing all $F$. solani non-SDS-causing isolates with a single nucleotide insertion. The positions of the five $F$. solani non-SDS-causing isolates with multiple insertions within the third clade varied depending on the analysis method. Bootstrap analysis with 1,000 replicates indicated strong support for the three major clades that resulted from neighbor-joining analysis in which gapped characters were excluded (Fig. 3). The same tree topology formed when gaps were treated as missing data in the analysis. The difference between the neighbor-joining tree and the most parsimonious tree was in the position of the isolate Fsph-2. This isolate was a sister taxon to the Lupine-Cucurbit subclade in the neighbor-joining tree, but it was grouped with isolates W8-13RI and 6-36 in the most parsimonious tree. For UPGMA, Fsph-2 was grouped with isolate 5-lupine, and the branches within the clade were weakly supported (data not shown). The best maximumlikelihood tree (data not shown) has the same topology as the neighbor-joining tree when gapped characters were excluded from the analysis (617 characters remained). When gaps were treated as missing data, the resolution of the third clade was improved, but an

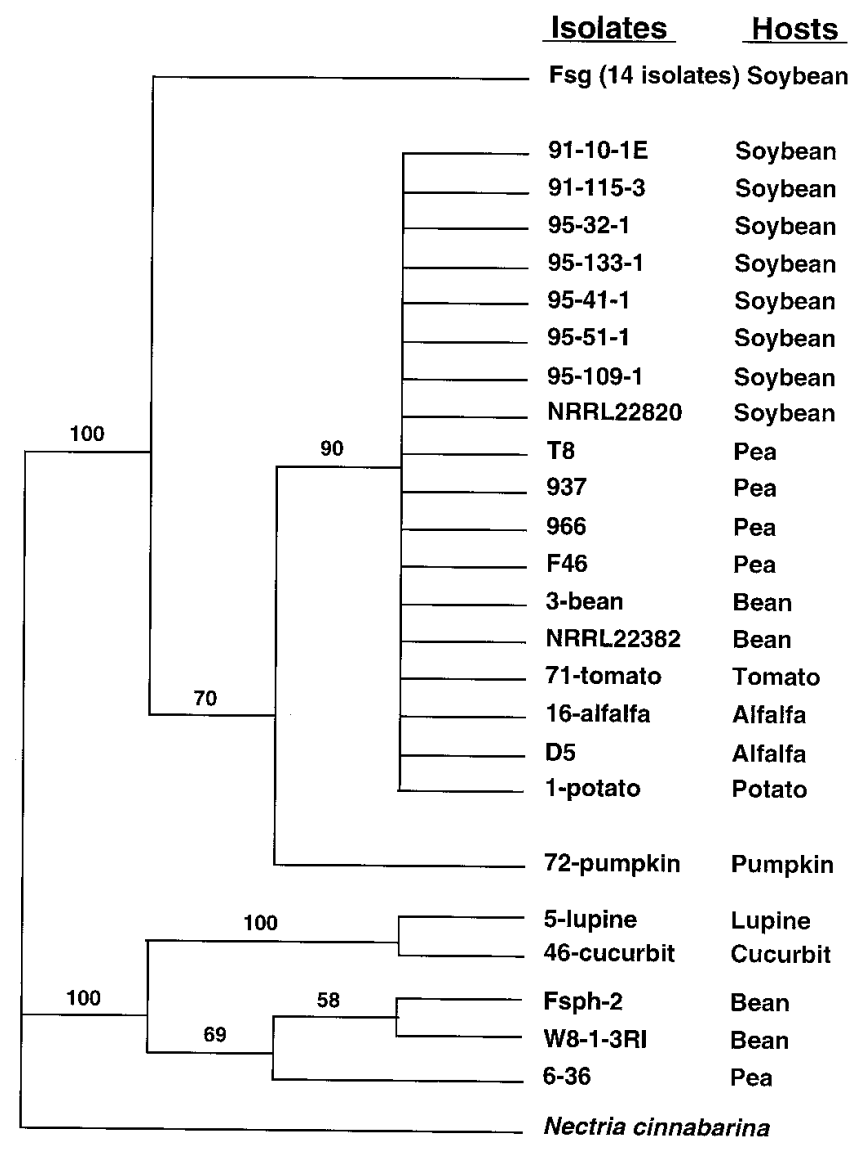

Fig. 2. Maximum parsimony analysis of all sequenced Fusarium solani $\mathrm{f}$. sp. glycines (Fsg) and $F$. solani non-sudden death syndrome-causing isolates based on the partial sequences of the mitochondrial small subunit rRNA gene. Nectria cinnabarina was used as an outgroup to root the tree. A single most parsimonious tree was obtained from a heuristic random-sequence addition search, with gaps coded as a fifth character state. Tree length $=214$; consistency index $=0.8832$; and retention index $=0.9471$. Bootstrap values $>50 \%$ that resulted from 1,000 bootstrap replicates are shown above branches. isolate from cucurbit (46-cucurbit) was grouped with isolates from bean (Fsph-2) and pea (6-36), while an isolate from lupine (5-lupine) was a sister taxon to this group. In the most parsimonious tree, isolates 46-cucurbit and 5-lupine formed a subgroup (Fig. 2) with a significant bootstrap value $(100 \%)$.

\section{DISCUSSION}

In this study, biological characterizations, including culture morphology, pathogenicity, and culture filtrate toxicity tests, were used to compare isolates of $F$. solani $\mathrm{f}$. sp. glycines and other $F$. solani that did not cause SDS in soybean. In general, most of the $F$. solani f. sp. glycines isolates produced blue pigment on PDA, but some of the $F$. solani isolates appeared blue and were similar to $F$. solani f. sp. glycines isolates, although they did not cause SDS symptoms in both pathogenicity and culture filtrate toxicity tests. $F$. solani $\mathrm{f}$. sp. glycines isolates caused greater foliar disease symptoms than other $F$. solani isolates when plants were inoculated or cuttings were placed in cell-free culture filtrates. The toxin or toxins responsible for SDS symptoms found in cell-free culture filtrates of $F$. solani f. sp. glycines cultures is unique to these isolates but not to other non-SDS-causing $F$. solani isolates.

From the molecular approach, our genetic and phylogenetic analyses strongly support the existence of three distinct clades among the $F$. solani isolates used in our study. All F. solani f. sp. glycines isolates $(n=14)$ from soybeans had identical sequences of the amplified DNA fragment from the mtSSU rDNA region. This may mean either that $F$. solani f. sp. glycines is more recently devel-

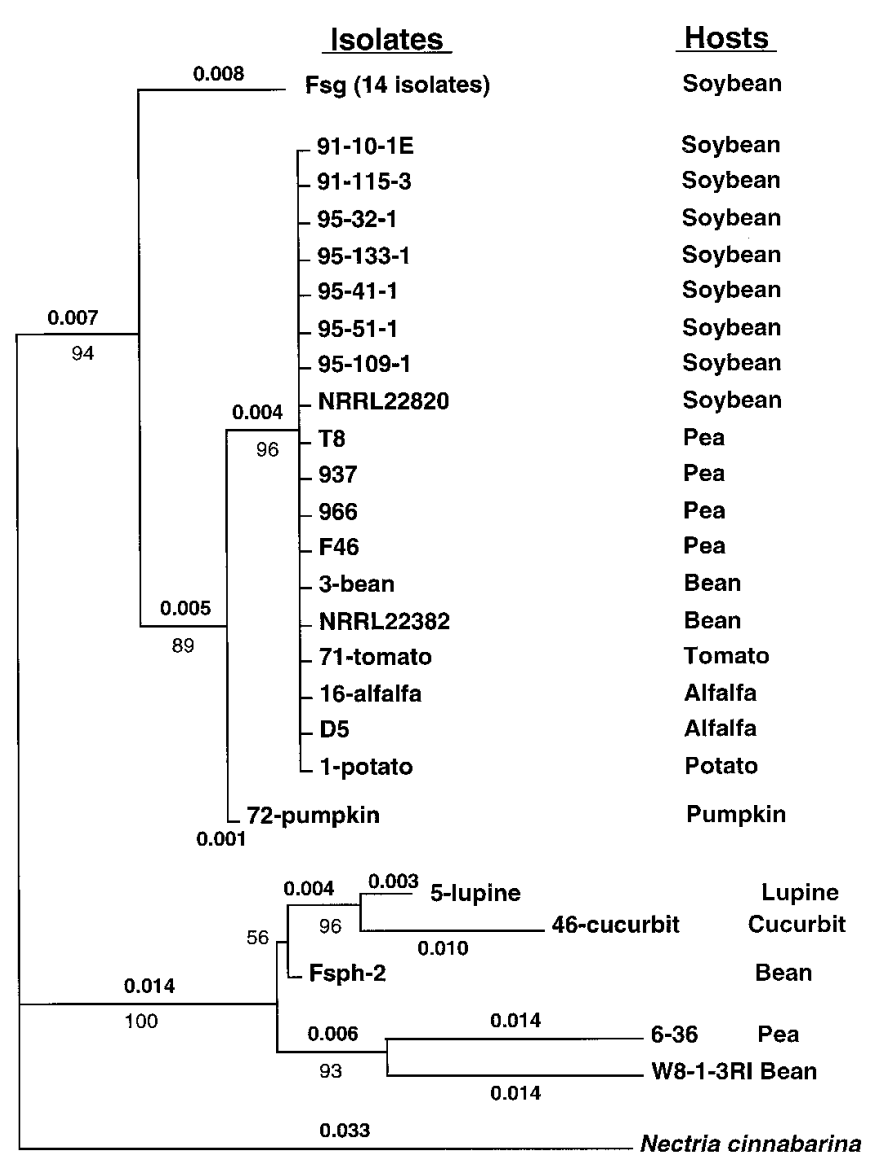

Fig. 3. Neighbor-joining analysis of all sequenced Fusarium solani f. sp. glycines (Fsg) and F. solani non-sudden death syndrome-causing isolates based on the partial sequences of the mitochondrial small subunit rRNA gene. Bootstrap values $>50 \%$ that resulted from 1,000 replicates are shown under branches, while values of branch length are shown over branches, except for isolates 46-cucurbit and W8-1-3RI. Total number of characters applied was 617 . 
oped or that the amplified region is highly conserved in the mitochondrial genome of $F$. solani. It was intriguing to find that there were two groups of $F$. solani non-SDS-causing isolates, in view of the sequence divergence and the presence and absence of multiple insertions in the amplified fragment. The first group had only a single nucleotide insertion when compared to the sequence of $F$. solani f. sp. glycines. This insertion also was found in the second group of $F$. solani non-SDS-causing isolates, which, in contrast, also had multiple insertions in two regions of the amplified fragments (Fig. 1). The genetic distance value between $F$. solani nonSDS-causing isolates with single insertion and $F$. solani $\mathrm{f}$. sp. glycines was much smaller (0.016) than that between $F$. solani non-SDS-causing isolates with single and multiple insertions (0.040). In fact, this latter distance was identical to that observed between $F$. solani non-SDS-causing isolates with multiple insertions and $F$. solani $\mathrm{f}$. sp. glycines. In view of the sequence similarity and the absence of multiple insertions, the most parsimonious explanation is that both $F$. solani $\mathrm{f}$. sp. glycines and $F$. solani non-SDS-causing isolates with a single insertion evolved from a recent common ancestor closely related to $F$. solani non-SDScausing isolates with multiple insertions. According to this scheme, sequences of the multiple insertions might, in fact, have existed in the ancestral species of $F$. solani and were subsequently lost through the course of evolution that led to the common ancestor of $F$. solani f. sp. glycines and $F$. solani non-SDS-causing isolates with single nucleotide insertion. Such a relationship among the three groups ( $F$. solani $\mathrm{f}$. sp. glycines, $F$. solani non-SDS-causing isolates with single insertion, and $F$. solani non-SDS-causing isolates with multiple insertions) is consistent in all analyses in the present study (Figs. 2 and 3). Furthermore, the sequences of the insertions between nucleotide positions 77 and 100 of $F$. solani $\mathrm{f}$. sp. glycines were highly similar among the five $F$. solani non-SDS-causing isolates. In contrast, the sequences of the insertions between nucleotide positions 474 and 502 of $F$. solani $\mathrm{f}$. sp. glycines varied both in length and character states among these five isolates.

The finding that 18 of the $19 \mathrm{~F}$. solani non-SDS-causing isolates with a single insertion studied, from various hosts, had identical sequences for the amplified fragment indicated that these isolates may have evolved before their host specialization. The one that showed a difference was an isolate from pumpkin (72-pumpkin). It would be interesting to study more isolates from pumpkin to see if they are host specific and also closely related to the common $F$. solani non-SDS-causing isolates. Although the five isolates with multiple insertions formed a strongly supported clade (bootstrap value $=100 \%$; Figs. 2 and 3), their relative position within the clade differed depending on the method of analysis used. Most informative characters for resolving the relationship among these five isolates were contributed by the sequences of the insertions. Gaps could not be treated as a new character state when we set the optimality criterion to maximum likelihood or distance in PAUP; therefore, the number of informative characters in the regions with insertions were reduced. From the maximum parsimony analysis in which gaps were treated as a new character state, isolates from lupine (5-lupine) and cucurbit (46-cucurbit) were closely related (bootstrap value of these group $=100 \%$ ) because they shared more synapomorphic characters. This relationship also was resolved in the maximum-likelihood and neighbor-joining analyses. However, the relationship with other isolates in this clade was poorly resolved in all methods of analysis. More informative characters are needed to improve the resolution within this clade. The results were not significantly improved when the gaps were either treated as missing data or excluded from the analysis.

The variations in both length and sequence of the amplified fragment of the five isolates with multiple insertions suggests that these isolates have a longer evolutionary history than the $F$. solani f. sp. glycines and $F$. solani non-SDS-causing isolates with a single nucleotide insertion.
Isolates of $F$. solani from beans and soybeans have been reported to be similar based on nuclear rDNA sequence (27). However, extensive studies comparing biological and pathological characteristics on these two groups of $F$. solani have shown how they differ and why F. solani f. sp. glycines should not be grouped with $F$. solani $\mathrm{f}$. sp. phaseoli (30). In our study, four $F$. solani $\mathrm{f}$. sp. phaseoli isolates were sequenced. Two of them (3-bean and NRRL 22382) had identical sequences and were grouped with the F. solani non-SDS-causing isolates that had a single nucleotide insertion. The other two isolates (Fsph-2 and W8-1-3RI) had multiple insertions. However, one isolate, received as $F$. solani f. sp. phaseoli, had an identical sequence with $F$. solani $\mathrm{f}$. sp. glycines in the amplified mtSSU region (data not shown). This isolate also caused SDS foliar symptoms in pathogenicity tests. Further experiments are being conducted to determine if this isolate is indeed $F$. solani f. sp. glycines. More isolates need to be analyzed to determine the phylogenetic relationship between $F$. solani f. sp. glycines and F. solani f. sp. phaseoli.

Characterization of the population structure of fungal pathogens is important for understanding an organism's biology and for developing disease-control strategies (24). Phylogenetic relationships among individuals are one of the components of population structure (18). As other genes besides the mtSSU rRNA gene are sequenced within the $F$. solani complex, a better phylogenetic and population analysis will be possible and may provide more insight as to the phylogenetic relationship of isolates in this complex. The information obtained in this current study will aid in the molecular identification and detection of $F$. solani f. sp. glycines. Based on our sequence data, a pair of primers (Fsg1 and Fsg2; Fig. 1) was developed (22), and their application for the specific detection of $F$. solani f. sp. glycines from field samples is in progress.

\section{ACKNOWLEDGMENTS}

This research was partially supported by a grant from the Illinois Soybean Checkoff Board, Project 96-22-167-3. We thank everyone who provided fungal isolates; I. Kornfield and J. B. Sinclair for their critical review of the manuscript; K. O'Donnell for sharing unpublished data and suggestions for improving the manuscript; and G. Olsen, X. Chen, and W. Chen for helpful discussions.

\section{LITERATURE CITED}

1. Achenbach, L. A., Patrick, J., and Gray, L. 1996. Use of RAPD markers as a diagnostic tool for the identification of Fusarium solani that cause soybean sudden death syndrome. Plant Dis. 80:1228-1232.

2. Brown, W. N., Geroge, M., Jr., and Wilson, A. C. 1979. Rapid evolution of animal mitochondrial DNA. Proc. Natl. Acad. Sci. USA 76:19671971.

3. Bruns, T. D., and Szaro, T. M. 1992. Rate and mode differences between nuclear and mitochondrial small-subunit rRNA genes in mushrooms. Mol. Biol. Evol. 9:836-855.

4. Bruns, T. D., White, T. J., and Taylor, J. W. 1991. Fungal molecular systematics. Annu. Rev. Ecol. Syst. 22:525-564.

5. Collins, R. A., and Lambowitz, A. M. 1983. Structural variations and optional introns in the mitochondrial DNAs of Neurospora strains isolated from nature. Plasmid 9:53-70.

6. Domsch, K. H., Gams, W., and Anderson, T.-H. 1980. Compendium of soil fungi. Academic Press, London.

7. Felsenstein, J. 1985. Confidence limits on phylogenies: An approach using the bootstrap. Evolution 39:783-791.

8. Garber, R. C., and Yoder, O. C. 1984. Mitochondrial DNA of the filamentous ascomycete Cochliobolus heterostrophus. Curr. Genet. 8:621628 .

9. Guadet, J., Julien, J., Lafay, J. F., and Brygoo, Y. 1989. Phylogeny of some Fusarium species, as determined by large-subunit rRNA sequence comparison. Mol. Biol. Evol. 6:227-242.

10. Hartman, G. L., Huang Y. H., Nelson, R. L., and Noel, G. R. 1997. Germ plasm evaluation of Glycine max for resistance to Fusarium solani, the causal organism of sudden death syndrome. Plant Dis. 81:515-518.

11. Hartman, G. L., Noel, G. R., and Gray, L. E. 1995. Occurrence of soybean sudden death syndrome in east-central Illinois and associated yield losses. Plant Dis. 79:314-318. 
12. Hillis, D. M., Moritz, C., and Mable, B. K. 1996. Molecular systematics. 2nd ed. Sinauer Associates Inc., Sunderland, MA.

13. Kim, D. H., Martyn, R. D., and Magil, C. W. 1992. Restriction fragment length polymorphism groups and physical map of mitochondrial DNA from Fusarium oxysporum f. sp. niveum. Phytopathology 82:346-353.

14. Kim, D. H., Martyn, R. D., and Magil, C. W. 1993. Mitochondrial DNA (mtDNA) - Relatedness among formae speciales of Fusarium oxysporum in Cucurbitaceae. Phytopathology 83:91-97.

15. Kimura, M. 1980. A simple method for estimating evolutionary rate of base substitutions through comparative studies of nucleotide sequences. J. Mol. Evol. 16:111-120.

16. Kistler, H. C., Bosland, P. W., Benny, U., Leong, S., and Williams, P. H. 1987. Relatedness of strains of Fusarium oxysporum from crucifers measured by examination of mitochondrial and ribosomal DNA. Phytopathology 77:1289-1293.

17. Kozlowski, M., and Stepien, P. P. 1982. Restriction enzyme analysis of mitochondrial DNA of members of the Genus Aspergillus as an aid in taxonomy. J. Gen. Microbiol. 128:471-476.

18. Leung, H., Nelson, R. J., and Leach, J. E. 1993. Population structure of plant pathogenic fungi and bacteria. Pages 157-204 in: Advances in Plant Pathology. J. H. Andrews and I. C. Tommerup, eds. Academic Press, London.

19. Li, K. N., Rouse, D. I., and German, T. L. 1994. PCR primers that allow intergenetic differentiation of ascomycetes and their application to Verticillium spp. Appl. Environ. Microbiol. 60:4324-4331.

20. Li, S., Cullen, D., Hjort, M., Spear, R., and Andrews, J. H. 1996. Development of an oligonucleotide probe for Aureobasidium pullulans based on the small subunit rRNA gene. Appl. Environ. Microbiol. 62:1514-1518.

21. Li, S., Hartman, G. L., and Gray, L. E. 1998. Chlamydospore formation, production, and nuclear status in Fusarium solani f. sp. glycines soybean sudden death syndrome-causing isolates. Mycologia 90:414-421.

22. Li, S., Hartman, G. L., and Tam, Y. K. 1998. Molecular comparison of $\mathrm{Fu}$ sarium solani $\mathrm{f}$. sp. glycines to other $F$. solani based on the mitochondrial small subunit rDNA sequences. (Abstr.) Phytopathology 88(suppl.):S53.

23. Li, S., Hartman, G. L., and Widholm, J. M. 1999. Viability staining of soybean suspension cultured cells and a stem-cutting assay to evaluate phytotoxicity of Fusarium solani culture filtrates. Plant Cell Rep. 18: 375-380.

24. Malvick, D. K., and Percich, J. A. 1998. Genotypic and pathogenic diversity among pea-infecting strains of Aphanomyces euteiches from the central and western United States. Phytopathology 88:915-921.

25. Nelson, B. D., and Hansen, J. M. 1997. Reaction of soybean cultivars to iso- lates of Fusarium solani from the Red River Valley. Plant Dis. 81:664-668.

26. O'Donnell, K. 1996. Progress towards a phylogenetic classification of Fusarium. Sydowia 48:57-70.

27. O'Donnell, K., and Gray, L. E. 1995. Phylogenetic relationships of the soybean sudden death syndrome pathogen Fusarium solani f. sp. phaseoli inferred from rDNA sequence data and PCR primers for its identification. Mol. Plant-Microbe Interact. 8:709-716.

28. O’Donnell, K., Kistler, H. C., Cigelnik, E., and Ploetz, R. C. 1998. Multiple evolutionary origins of the fungus causing Panama disease of banana: Concordant evidence from nuclear and mitochondrial gene genealogies. Proc. Natl. Acad. Sci. USA 95:2044-2049.

29. Rayner, R. W. 1970. A Mycological Colour Chart. Commonwealth Mycological Institute and British Mycological Society, Kew, England.

30. Roy, K. W. 1997. Fusarium solani on soybean roots: Nomenclature of the causal agent of sudden death syndrome and identity and relevance of F. solani form B. Plant Dis. 81:259-266.

31. Roy, K. W., Lawrence, G. W., Hodges, H. H., McLean, K. S., and J. F. Killebrew, J. F. 1989. Sudden death syndrome of soybean: Fusarium solani as incitant and relation of Heterodera glycines to disease severity. Phytopathology 79:191-197.

32. Rupe, J. C. 1989. Frequency and pathogenicity of Fusarium solani recovered from soybeans with sudden death syndrome. Plant Dis. 73:581-584.

33. Rupe, J. C., Becton, C. M., Williams, K. J., and Yount, P. 1996. Isolation, identification and evaluation of fungi for the control of sudden death syndrome of soybean. Can. J. Plant Pathol. 18:1-6.

34. Song, H. S., Lim, S. M., and Clark, J. M., Jr. 1993. Purification and partial characterization of a host-specific pathotoxin from culture filtrate of Septoria glycines. Phytopathology 83:659-661.

35. Steven, B., Lee, S., and Taylor, J. W. 1990. Isolation of DNA from fungal mycelia and single spores. Pages 282-287 in: PCR Protocols: A Guide to Methods and Applications. M. A. Innis, D. H. Gelfand, J. J. Sninsky, and T. J. White, eds. Academic Press, New York.

36. Thompson J. D., Higgins, D. G., and Gibson, T. J. 1994. CLUSTAL W: Improving the sensitivity of progressive multiple sequence alignment through sequence weighting, position-specific gap penalties and weight matrix choice. Nucleic Acids Res. 22:4673-4680.

37. Vaillancourt, L. J., and Hanau, R. M. 1992. Genetic and morphological comparisons of Glomerella (Colletotrichum) isolates from maize and from sorghum. Exp. Mycol. 16:219-229.

38. Wrather, J. A., Chambers, A. Y., Fox, J. A., Moore, W. F., and Sciumbato, G. L. 1995. Soybean disease loss estimates for the southern United States, 1974 to 1994 . Plant Dis. 79:1076-1079. 